\title{
The Drought Calculator: Decision Support Tool for Predicting Forage Growth During Drought
}

\author{
Gale H. Dunn, ${ }^{1,+}$ Megan Gutwein, ${ }^{2}$ Timothy R. Green, ${ }^{3}$ Ashley Menger, ${ }^{4}$ and Jeff Printz ${ }^{5}$
}

Authors are ${ }^{1}$ Soil Scientist, ${ }^{2}$ Biological Science Technician, and ${ }^{3}$ Hydrologist, USDA-ARS, Fort Collins, CO 80526, USA; ${ }^{4}$ Graduate Student, Colorado State University, Fort Collins, CO 80524, USA; and ${ }^{5}$ Range Conservationist, USDA-NRCS, Bismarck, ND 58502, USA.

\begin{abstract}
The Drought Calculator (DC), a spreadsheet-based decision support tool, was developed to help ranchers and range managers predict reductions in forage production due to drought. Forage growth potential (FGP), the fraction of historical average production, is predicted as a weighted average of monthly precipitation from January through June. We calibrated and evaluated the DC tool in the Great Plains of the United States, using FGP and precipitation data from Colorado (CO), North Dakota (ND), and Wyoming (WY). In CO, FGP was most sensitive to precipitation in April and May, in ND to precipitation in April and June, and in WY to precipitation in April, May, and June. Weights in these months ranged from 0.16 to 0.52. Prediction was better for CO and WY than for ND. When January-June precipitation was used, the tool correctly predicted $83 \%$ of the years with FGP reduced by drought for CO, $82 \%$ for WY, and only $67 \%$ for ND. Positive values of the True Skill Statistic ( 0.53 for CO, 0.42 for WY, and 0.17 for ND) indicate that FGP was classified as above or below average better than random selection. Predicting FGP earlier than April in CO and WY will require accurate forecasts of April-June precipitation. Use of the DC is most limited by insufficient forage data to determine the site-specific relationships between FGP and monthly precipitation. Even so, the decision tool is useful for discriminating drought effects on FGP classification being above or below the long-term average, and it provides a quantitative prediction to producers for their destocking decisions in drought years.
\end{abstract}

Key Words: cross validation, forage, precipitation, rangeland drought, stocking decisions

\section{INTRODUCTION}

Ranchers and range managers on the arid central Great Plains regularly experience periods of drought that range from mild to severe and last for a single season to multiple years (Dahl 1963). These drought periods can substantially reduce the amount of native range forage available for livestock. Consequently, ranchers and range managers would benefit from a decision support tool that estimated coming season forage growth potential (Smoliak 1986; Andales et al. 2006; Smart et al. 2007). When it is apparent to all ranchers that forage is insufficient, selling off livestock generally results in lower prices at the stockyard (Eckblad 2012). Managers could potentially sell stock earlier when prices are higher.

Research was funded in part by the USDA-Risk Management Agency

Data sets for Colorado site were provided by the Shortgrass Steppe Long Term Ecological Research group, a partnership between Colorado State University, the US Department of Agriculture, the Agricultural Research Service, and the U.S. Forest Service Pawnee National Grassland. Significant funding for these data was provided by the National Science Foundation Long Term Ecological Research program (NSF Grant DEB-0823405).

The authors appreciate the many helpful comments from anonymous reviewers and editors.

Mention of a proprietary product does not constitute an endorsement, a guarantee, or warranty of the product by the USDA.

†Dr. Gale Dunn led the project, developed the Drought Calculator, and guided this paper to submission. Gale passed away on 3 May 2012 after a long bout with cancer.

Correspondence: Timothy Green, USDA-ARS, Fort Collins, C0 80526, USA. Email: Tim. Green@ars.usda.gov

Manuscript received 16 July 2012; manuscript accepted 10 July 2013

(c) 2013 The Society for Range Management
Supplementing feed to get through to an autumn sell date is another option during drought, but this is expensive (Eckblad 2012). Doing nothing can be detrimental to livestock weight gains and hence profit and can also lead to serious environmental degradation of the range (Thurow and Taylor 1999).

A functional decision support tool must be simple to use and require only readily available information (Parker and Campion 1997). Greater accuracy might be possible with less readily available information or a complicated model, but users may grow frustrated and decide not to use it if it is time consuming to acquire and enter the required information. Further, many users will not trust a model enough to modify management unless they understand and agree with the logic that drives the predictions (Wilkerson et al. 2002). Accuracy of a decision tool is best judged by whether a user will make better decisions with the tool than without it. The user must consider the improvement in decision worth the effort of collecting inputs and entering these in the tool.

Our goal was to develop a decision support tool that is simple and easy to use and predicts coming-season forage growth potential (FGP) accurately enough to help ranchers and range managers make stocking decisions early in the season during drought years. The tool we developed, the Drought Calculator (DC), ${ }^{1}$ is spreadsheet based, and the main objective of this research was to evaluate its accuracy. In this study, FGP represents the maximum aboveground biomass (forage) during the growing season. Observed data from three sites were the peak standing crop (PSC), or the peak value of aboveground

${ }^{1}$ Available at http://arsagsoftware.ars.usda.gov. 
biomass at a point in the growing season. In developing our model for predicting FGP in the DC, we began with a simple concept: average precipitation in key months results in average production. Further, we assumed that any deviation from average precipitation will result in a deviation of FGP from the average.

Native range forage production is influenced by many environmental factors (Briggs and Knapp 1995), including climatic variability, aspect (Gillen and Sims 2006), soil type, landscape, soil fertility, and temperature. However, many scientists agree that the single most limiting environmental factor on the Great Plains is soil moisture, which is directly related to precipitation (Currie and Peterson 1966; Lauenroth and Sala 1992; Biondini and Manske 1996; Frank et al. 1996; Schwinning et al. 2005). It would follow then, that precipitation is a good environmental factor for predicting FGP. In addition, several researchers have shown that certain months prior to PSC have greater influence on PSC than other months (Currie and Peterson 1966; Smoliak 1956, 1986; Frank et al. 1996; Heitschmidt et al. 2005; Derner and Hart 2007; Smart et al. 2007). Relationships between spring precipitation and FGP are typically nonlinear with a weak linear relationship between FGP and low precipitation (Milchunas et al. 1994). Conversely, large percentages of the interannual variability in FGP (e.g., $55-97 \%$ for crested wheatgrass) may be explained using linear regression with April and/or May precipitation (Currie and Peterson 1966).

Based on these findings and our own analyses of PSC compared to precipitation over the whole year, the growing season, and months prior to PSC (Wiles et al. 2011), we developed a model that predicts forage growth in the coming season months in advance. Our goal was to develop a linear decision tool to help ranchers cope with drought by predicting if FGP will be reduced due to limited precipitation and, if so, by how much. For this reason, forage production and monthly precipitation were standardized with respect to average forage production and average monthly precipitation, respectively, with a value of 1.0 equaling average conditions for each location over the period of record. The model predicts deviation of FGP from the long-term average based on deviations from long-term average precipitation for spring months. The significance of deviations can vary by month. Since we are predicting FGP during drought when it is necessary for managers to make difficult decisions regarding stocking rates, we concentrate on predicting FGP only if lessthan-average production is expected.

Although our hypothesis that springtime precipitation influences growing season forage production may apply across the northern Great Plains, the significance of precipitation during spring months varies among locations. Consequently, in addition to developing the DC, we developed a spreadsheet tool that selects parameters for the model that predicts forage production. Parameters are selected using historical forage production and precipitation data at a location. In this article, we describe the predictive model of the DC and our method of selecting parameters. We also use data from three research stations (see Methods) to evaluate the accuracy of predictions with the DC model and our calibration method.

\section{METHODS}

\section{Data for Evaluation}

Predictive accuracy of the model and the parameters selected with our optimization algorithm, both described below, were evaluated using data from three rangeland research stations: 1) the Central Plains Experimental Range near Nunn, Colorado (CO), 2) the Central Grasslands Research Extension Center near Streeter, North Dakota (ND), and 3) the High Plains Grassland Research Station near Cheyenne, Wyoming (WY). Precipitation and forage data were collected at each of these sites. Forage production data were averaged each year over all plots within a station to remove individual grazing treatment effects. In this way, the annual FGP values used in our analyses represent average conditions for each station, and variations in treatments across sites (lightly, moderately, and heavily grazed or ungrazed) were reduced. Since the relationship between monthly precipitation and forage production varies between these locations, the model was calibrated and evaluated separately for each location.

The Central Grasslands Extension Research Center is at a mean elevation of $607 \mathrm{~m}$ and has an average annual precipitation of $434 \mathrm{~mm}, 80 \%$ of which falls between 1 April and 30 September (North Dakota Agricultural Weather Network 2008). Biondini et al. (1998) provided a detailed description of the topography, soil morphology, climate, and range. The current native range at the Research Center is described as a mixed-grass prairie. Kentucky bluegrass (Poa pratensis L.), western wheatgrass (Agropyron smithii Rydb.), green needlegrass (Stipa viridula Trin.), sun sedge (Carex heliophia Mack.), and obtuse sedge (Carex obtusata Lilj.) are the dominant plants (Biondini et al. 1998). Data on PSC of grazed and ungrazed treatments from 1989 through 2007 were used for this study (B. Patton, personal communication, November 2012). PSC, averaged over the two treatments, was $2438 \pm 504 \mathrm{~kg} \cdot \mathrm{ha}^{-1}$.

The High Plains Grassland Research Station is at an elevation of $1850 \mathrm{~m}$, and the long-term average annual precipitation is $381 \mathrm{~mm}, 80 \%$ of which falls between 1 April and 30 September (Western Regional Climate Center 2008). According to Derner and Hart (2007), the dominant native grasses on this mixed-grass prairie are western wheatgrass (Agropyron smitii), needle-and-thread (Stipa comata), prairie junegrass (Koeleria macranatha [Ledeb.] J.A. Schultes), and blue grama (Bouteloua gracilis [H.B.K.] Lag. Ex Griffiths). Derner and Hart (2007) provided a detailed description of the study site, including experimental design of the research site, soils, and climate. Data on PSC with two different levels of grazing from 1991 through 1999 and 2001 through 2012 were used for this study. Average production was $1429 \pm 628$ $\mathrm{kg} \cdot \mathrm{ha}^{-1}$. We calculated the observed PSC separately for the lightly grazed and moderately grazed treatments at the station and used the average value for each year.

The Central Plains Experimental Range is at an elevation of $1650 \mathrm{~m}$, with a mean annual precipitation of $320 \mathrm{~mm}$, the majority of which occurs during the April to September growing season. Blue grama (B. gracilis [H.B.K.] Lag. Ex Griffiths) is the dominant native vegetation on this shortgrass steppe site (Lauenroth and Sala 1992). Detailed descriptions of the site and experimental design are provided in the data set 
summary on the Shortgrass Steppe Long Term Ecological Research website (Colorado State University 2013). The average production was $823 \pm 303 \mathrm{~kg} \cdot \mathrm{ha}^{-1}$.

\section{Model}

The model theory for predicting forage production in the DC was based on a linear relationship between variation in standardized PSC $\left(\mathrm{kg} \cdot \mathrm{ha}^{-1}\right)$ and the variation in standardized precipitation when precipitation limits forage growth. The predicted variable was FGP, or forage production standardized to a value of one for average production at a location. Belowaverage FGP then was indicated by a value less than one, with the value representing the proportion of average production. Predictor variables were the total precipitation $(\mathrm{mm})$ during each month $\left(\mathrm{P}_{\text {month }}\right)$ standardized to a value of one for the average over the period of record $\left(\right.$ Pmean $\left._{\text {month }}\right)$. FGP was predicted as a weighted average of standardized precipitation by month from January to June for all years:

$$
\mathrm{FGP}=\sum_{\text {month=January }}^{\text {June }} \mathrm{w}_{\text {month }} \cdot \frac{\mathrm{P}_{\text {month }}}{\text { Pmean }_{\text {month }}}
$$

Equation 1a was used for quantification of model errors over all years ("all data" reported below). However, since the model was intended primarily for predicting FGP during drought, if the weighted average of precipitation was greater than one, FGP was set equal to one in the DC:

$$
\begin{array}{r}
\mathrm{FGP}=\sum_{\text {month }=\text { January }}^{\text {June }} \mathrm{w}_{\text {month }} \cdot \frac{\mathrm{P}_{\text {month }}}{\text { Pmean }_{\text {month }}} \\
\text { if } \sum_{\text {month }=\text { January }}^{\text {June }} \mathrm{w}_{\text {month }} \cdot \frac{\mathrm{P}_{\text {month }}}{\text { Pmean }_{\text {month }}} \leq 1 \\
\text { FGP }=1 \text { if } \sum_{\text {month =January }}^{\text {June }} \mathrm{w}_{\text {month }} \cdot \frac{\mathrm{P}_{\text {month }}}{\text { Pmean }_{\text {month }}}>1
\end{array}
$$

with

$$
\mathrm{w}_{\text {month }} \geq 0 \text { for all months }
$$

and

$$
\sum_{\text {month=January }}^{\text {June }} \mathrm{w}_{\text {month }}=1
$$

\section{Calibration}

We developed an optimization algorithm to determine the weights for each month $\left(\mathrm{w}_{\text {month }}\right)$ based on a set of observed precipitation and forage production data for a location (see Eq. 2). The algorithm minimizes the sum of squared errors between the predicted and observed values of FGP subject to the constraint that below-average FGP had to be predicted for more than $50 \%$ of the years that observed FGP was below average:

Minimize

$$
\sum_{i=1}^{n}\left(\text { FGPpred }_{i}-\text { FGPobs }_{i}\right)^{2}
$$

with

$$
\frac{1}{n} \sum_{i=1}^{n} \text { nbelow }_{i}>0.50
$$

where

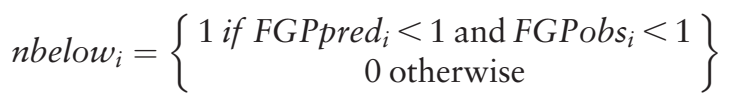

where $n=$ number of years of observations $F G P o b s_{i}=$ observed

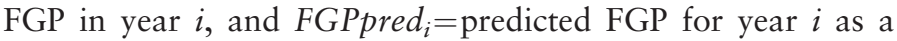
function of $\mathrm{w}_{\text {month }}$.

Optimization was implemented with the nonlinear solver engine in Microsoft Excel using the Generalized Reduced Gradient algorithm, automatic scaling, and a multistart search. Initial values must be specified for each monthly weight $\left(\mathrm{w}_{\text {month }}\right)$. The default values were 0.33 for April, May, and June and zero for all other months.

\section{Evaluation}

Ideally, a model is calibrated with one set of data and evaluated with an independent data set (Hawkins et al. 2003). With our limited data, however, predictive accuracy was evaluated with cross validation. With this method, the model is calibrated many times using different portions of the observations in the full data set and evaluated using the remaining portions. Cross validation gives a better estimate of how the model will predict in practice than of how well the model fits the original data set. We used leave-one-out cross validation, the best method of cross validation when data are very limited (Hawkins et al. 2003). In this case, the model is calibrated with one observation omitted, and then the omitted observation is predicted. This procedure is repeated until all observations in the data set have been predicted and the accuracy of those predictions is evaluated.

Besides evaluating the accuracy of FGP predictions in July (predictions made using actual precipitation in each month from January through June), we evaluated predictions throughout the season. We did this by replacing actual precipitation with average precipitation $\left(\mathrm{P}_{\text {month }} / \mathrm{Pmean}_{\text {month }}=1\right)$ for unknown precipitation of future months. For example, we predicted FGP in April using actual precipitation for January, February, and March and average precipitation for April $\left(\mathrm{P}_{\text {April }} / \mathrm{Pmean}_{\mathrm{April}}=1\right)$, May $\left(\mathrm{P}_{\text {May }} / \mathrm{Pmean}_{\text {May }}=1\right)$, and June $\left(\mathrm{P}_{\text {June }} / \mathrm{Pmean}_{\text {June }}=1\right)$. Accuracy of predictions throughout the season were evaluated with cross validation used for predictions with all months.

Cross-validation results were evaluated with measures that reflect the intended use of the model as a decision model and specifically a decision model that first classifies FGP as above or below average and then predicts a value only if FGP is expected to be below average. The measure of classification accuracy is the true skill statistic (TSS):

$$
\mathrm{TSS}=\frac{a}{(a+c)}+\frac{d}{(b+d)}-1
$$

This is the overall accuracy of classification corrected for success in guessing the correct classification (Allouche et al. 2006) and is calculated from an error matrix. The error matrix is the number of years ( $a, b, c$, and $d$ ) of each possible classification of a prediction based on the observed and 

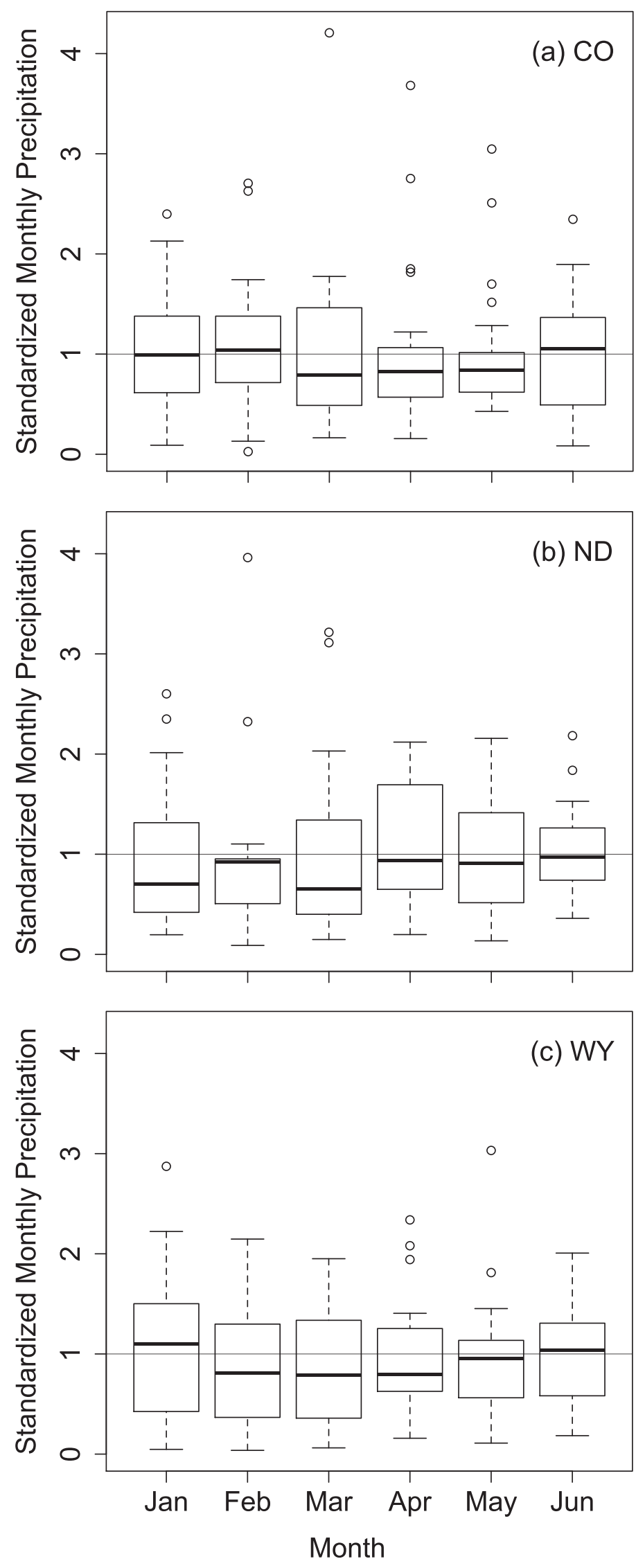

Figure 1. Variability in monthly precipitation (standardized by the long-term monthly mean) from January to July at the ND, WY, and CO locations used to test the accuracy of a model for predicting forage growth potential. predicted FGP. The letter "a" indicates both observed and predicted FGP $<1$, " $b$ " is observed FGP $\geq 1$ but predicted FGP $<1$, "c" is observed FGP $<1$ but predicted FGP $\geq 1$, and " $\mathrm{d}$ " indicates both observed and predicted FGP $\geq 1$. The TSS ranges from -1 to 1 with a value of one if all observations are correctly classified. Values of less than zero indicate classification is not better than guessing.

We also calculated the producer's and user's accuracies of observed and predicted classes of FGP (Congalton 1991). The producer's accuracies are the first two components of the TSS (Eq. 3). The first component is the producer's accuracy for observed FGP $<1$, the accuracy of predicting the number of years with below-average FGP, and the second component is the producer's accuracy for observed FGP $\geq 1$. User's accuracies are the accuracy of the predicted rather than the observed class of FGP. For example, for predicted FGP $<1$, the user's accuracy is $a /(a+b)$.

Agreement between observed and predicted values of FGP was quantified by calculating the mean bias,

$$
\mathrm{MB}=\frac{1}{n} \sum_{i=1}^{\text {nyrs }}\left(\text { FGPpred }_{i}-\text { FGPobs }_{i}\right)
$$

and root mean squared error (RMSE),

$$
\text { RMSE }=\sqrt{\frac{1}{n} \sum_{i=1}^{n y r s}\left(\text { FGPpred }_{i}-\text { FGPobs }_{i}\right)^{2}}
$$

where terms were defined above (Eq. 2).

Mean bias (Eq. 4) is the average difference between predicted and observed values of FGP. RMSE (Eq. 5) indicates the size of the error relative to the mean of the observed values $<1$.

\section{RESULTS}

\section{Variability in Monthly Precipitation and Forage Production}

This model depends on the deviation of precipitation and FGP data from long-term historical averages. Monthly precipitation in all locations was skewed, that is, more frequently below than above the long-term historical average with a few years of very high precipitation (Fig. 1).

The distributions of $\mathrm{FGP}_{\text {obs }}$ generally differ from the distributions of monthly precipitation (Fig. 2). Note that the maximum $\mathrm{FGP}_{\text {obs }}$ is approximately 2.1 (Fig. 2), compared with a maximum standardized monthly precipitation of more than 4 (Fig. 1). Forage production is clearly limited by factors other than precipitation. FGP was less variable for ND than WY or CO. Production was below average for $9 \mathrm{yr}$ in ND, $11 \mathrm{yr}$ in WY, and $12 \mathrm{yr}$ in CO. Below-average production in WY ranged from 0.09 to 0.98 with production less than 0.80 for eight of those years. For ND, below-average production ranged from 0.55 to 0.99 but was less than 0.80 for only $3 \mathrm{yr}$. In CO, below-

Boxes show 25th, 50th (median), and 75th percentiles of the distributions, with whiskers extending to the maxima/minima or 1.5 times the interquartile ranges. Dots represent extreme values beyond the whiskers, if any. ND indicates North Dakota; WY, Wyoming; CO, Colorado. 


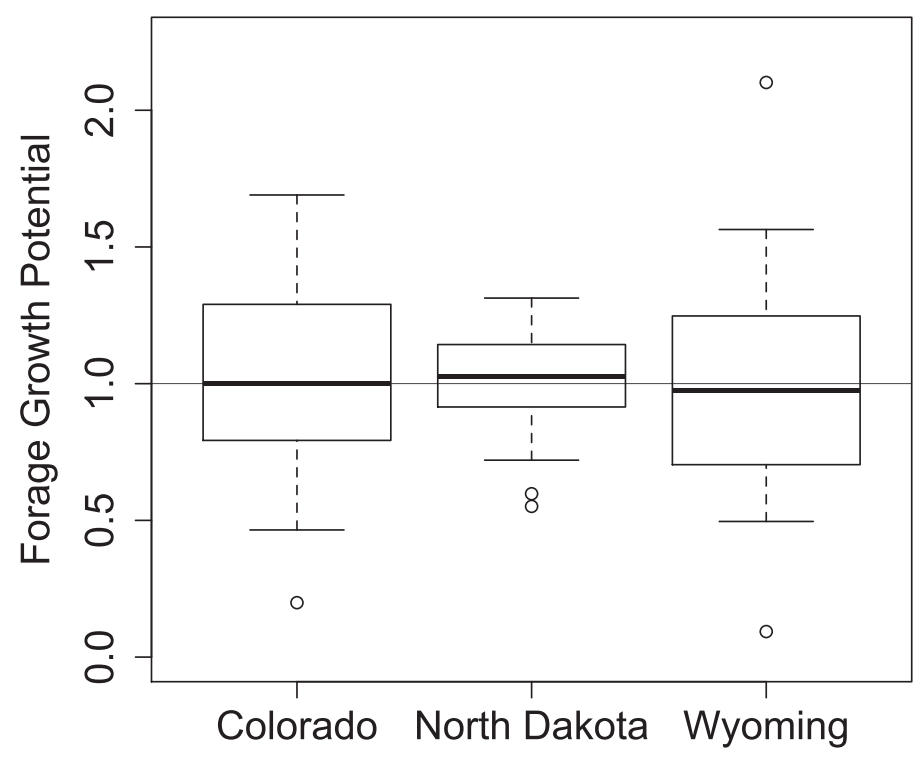

Figure 2. Variability in FGP for CO, ND, and WY. Box plots show the distributions of annual values of FGP (see caption for Fig. 1). FGP indicates forage growth potential; CO, Colorado; ND, North Dakota; WY, Wyoming.

average production ranged from 0.20 to 0.91 , with $7 \mathrm{yr}$ less than 0.80 .

\section{Significance of Monthly Precipitation}

Parameters for our calibration model indicate the sensitivity of FGP to precipitation that month. Variability in spring precipitation contributed the most to the variability in FGP.
In fact, FGP in WY varied with precipitation only in April, May and June (Table 1). Weights were less than 0.03 for January, February, and March. June precipitation had less influence on FGP $\left(\mathrm{w}_{\text {June }}=0.26\right)$ than April $\left(\mathrm{w}_{\text {April }}=0.36\right)$ and May $\left(\mathrm{w}_{\text {May }}=0.34\right)$.

More months of precipitation affected FGP in ND than in WY. Precipitation in April $\left(\mathrm{w}_{\text {April }}=0.16\right)$ and June $\left(\mathrm{w}_{\text {June }}=0.52\right)$ contributed the most to the variability in FGP. For ND, in contrast to WY, the weight for March $\left(w_{\text {March }}=0.13\right)$ was larger than the weight for May $\left(w_{\text {May }}=0.08\right)$, and January and February had a small contribution to the variability in FGP.

In $\mathrm{CO}$, all months except for February contributed somewhat to the variability in FGP. April $\left(\mathrm{W}_{\text {April }}=0.40\right)$ and May $\left(\mathrm{W}_{\text {May }}=0.21\right)$ were weighted the highest, with January also showing significant contribution $\left(\mathrm{W}_{\mathrm{Jan}}=0.16\right)$.

Cross validation generates as many sets of parameters as the number of observations, and similarity of the weights from model calibration and cross validation is one indication of how well the model will predict in practice. The mean of the parameters generated in the cross-validation study for WY matched the values generated with the model fit to the entire data set, or the calibration (Table 1). The largest standard deviation was consistently 0.01 . Mean weights from the cross validation for ND were within 0.01 of the values generated with the entire data set. The largest standard deviation was 0.05 for June. Mean weights from the $\mathrm{CO}$ cross validation were also within 0.01 of the calibration values. The largest standard deviation was 0.03 for January, March, and June.

Table 1. Model weights for each predictor month that represent the relative significance of precipitation in forage growth potential. Data sets of 19, 21, and 25 yr were used for calibration and cross validation at CO, ND, and WY locations, respectively. ${ }^{1}$

\begin{tabular}{|c|c|c|c|c|c|}
\hline \multirow[b]{3}{*}{ Location } & \multirow[b]{3}{*}{ Months } & \multicolumn{4}{|c|}{ Model parameters } \\
\hline & & \multirow[b]{2}{*}{ Calibration } & \multicolumn{3}{|c|}{ Cross validation } \\
\hline & & & Mean \pm SD & Minimum & Maximum \\
\hline \multirow[t]{6}{*}{$\mathrm{CO}$} & January & 0.158 & $0.153 \pm 0.031$ & 0.023 & 0.189 \\
\hline & February & 0.000 & $0.001 \pm 0.004$ & 0.000 & 0.020 \\
\hline & March & 0.138 & $0.141 \pm 0.028$ & 0.093 & 0.246 \\
\hline & April & 0.398 & $0.400 \pm 0.018$ & 0.361 & 0.473 \\
\hline & May & 0.212 & $0.209 \pm 0.023$ & 0.143 & 0.272 \\
\hline & June & 0.094 & $0.096 \pm 0.033$ & 0.000 & 0.195 \\
\hline \multirow[t]{6}{*}{ ND } & January & 0.044 & $0.042 \pm 0.018$ & 0.000 & 0.097 \\
\hline & February & 0.065 & $0.063 \pm 0.016$ & 0.013 & 0.085 \\
\hline & March & 0.131 & $0.129 \pm 0.033$ & 0.000 & 0.166 \\
\hline & April & 0.157 & $0.160 \pm 0.017$ & 0.130 & 0.206 \\
\hline & May & 0.085 & $0.077 \pm 0.030$ & 0.000 & 0.129 \\
\hline & June & 0.519 & $0.528 \pm 0.050$ & 0.400 & 0.673 \\
\hline \multirow[t]{6}{*}{ WY } & January & 0.000 & $0.002 \pm 0.005$ & 0.000 & 0.017 \\
\hline & February & 0.010 & $0.011 \pm 0.010$ & 0.000 & 0.040 \\
\hline & March & 0.029 & $0.028 \pm 0.010$ & 0.003 & 0.047 \\
\hline & April & 0.365 & $0.364 \pm 0.013$ & 0.321 & 0.383 \\
\hline & May & 0.339 & $0.337 \pm 0.010$ & 0.322 & 0.368 \\
\hline & June & 0.259 & $0.258 \pm 0.010$ & 0.235 & 0.277 \\
\hline
\end{tabular}

${ }^{1} \mathrm{SD}$ indicates standard deviation; CO, Colorado; ND, North Dakota; and WY, Wyoming. 


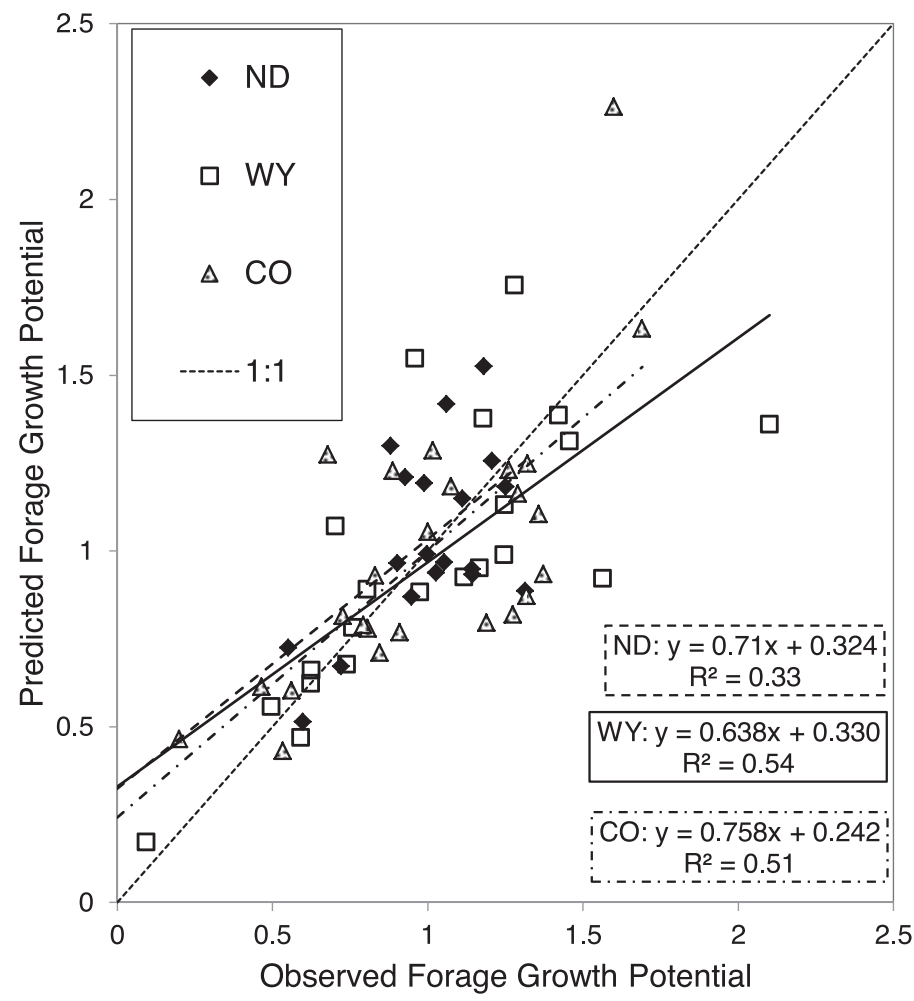

Figure 3. Predicted versus observed values of forage growth potential for $\mathrm{CO}, \mathrm{ND}$, and WY. Values greater than one are included here. CO indicates Colorado; ND, North Dakota; WY, Wyoming.

\section{Prediction of Forage Production}

Predicted and observed FGP values generated with weights from the model calibration are shown in Figures 3 and 4, and results of cross validation are shown in Table 1 . Some measures were calculated separately for observed classes of FGP because knowing whether FGP will be reduced by drought is useful information for a manager. If FGP will not be reduced, the decision will likely be to maintain the existing herd ("do nothing" or no destocking). Predicting the extent to which FGP exceeds one is not a goal of the DC, but such conditions may provide opportunities for temporary herd expansion (Torell et al. 2010). Error statistics were also computed for all observations (Fig. 3 and Table 2) because these statistics indicate how accurately the model predicts forage growth overall as well as any bias toward over- or underprediction.

The accuracy of classifying FGP as below or above average was measured with the true skill statistic (TSS) in Equation 3. If drought occurs, knowing how much FGP will be reduced is even more useful information. RMSE in Equation 5 quantifies the agreement between observed and predicted values of FGP. RMSE was calculated for observations of FGP $<1$ as well as all observations $(\mathrm{FGP} \geq 1)$ to emphasize how well the model describes the relationship between reduced FGP and precipitation compared to the overall relationship between FGP and precipitation (Table 3).

For ND, the overall RMSE was 0.22 for prediction with precipitation in all months and the TSS is small (0.17) yet indicates that prediction of years with FGP $<1$ would be better than guessing predicted values overall. For below-average observations, the calculated RMSE (0.07) indicates good

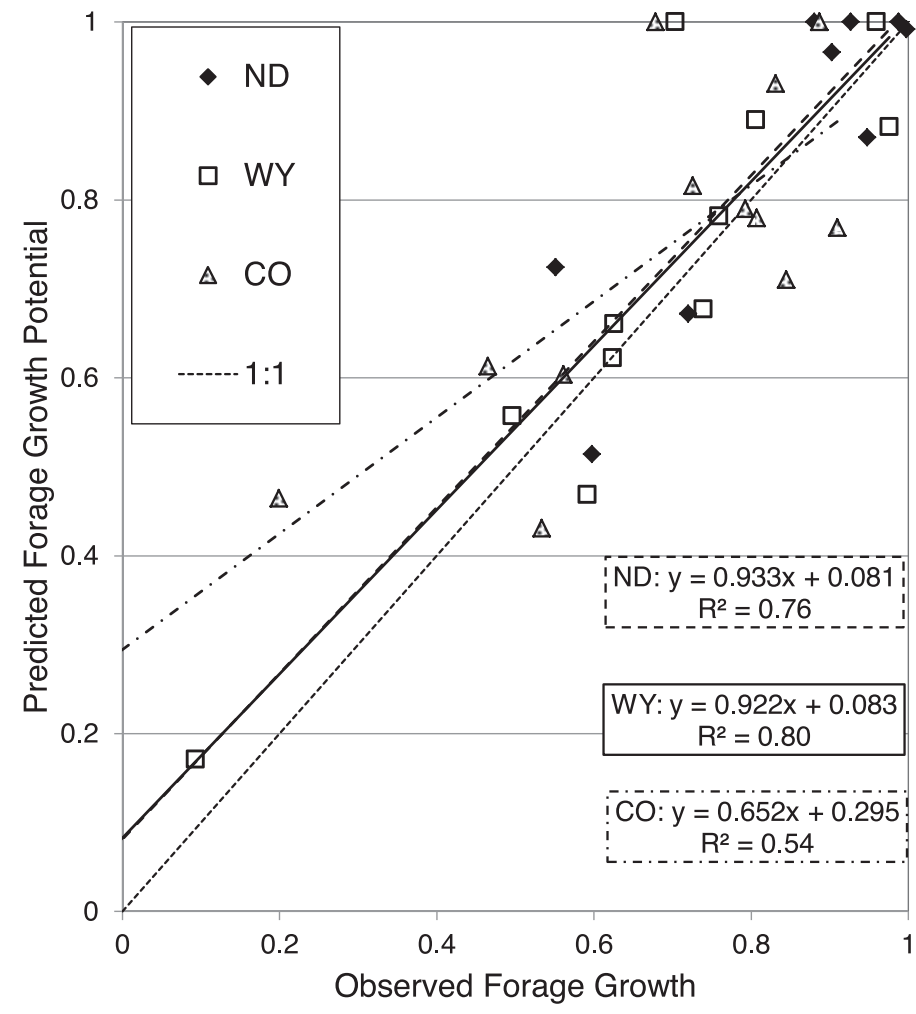

Figure 4. Predicted versus observed values of FGP when observed FGP $<1$ for CO, ND, and WY. Linear regressions show deviations from the 1:1 line. FGP indicates forage growth potential; CO, Colorado; ND, North Dakota; WY, Wyoming.

agreement between observed and predicted values. These contrasting results arise from the skewed distribution of observed FGP for ND. Many observations are close to one, and these observations can be misclassified as above average with a small error in prediction. In fact, the $\mathrm{MB}$ for $\mathrm{FGP}_{\text {obs }}<1$ was -0.01 , and the accuracy of predicting that FGP $<1$ (producer's accuracy) was $67 \%$. In contrast to ND, the model for WY classified $(T S S=0.42$ ) and predicted FGP well $(\mathrm{RMSE}=0.30$ and 0.09$)$. The producer's accuracy for WY $(82 \%)$ shows that WY predicted FGP $<1$ more accurately than the model for ND. Like the model for ND, the effect of reduced precipitation on FGP was underestimated. The MB for WY was -0.04 (Table 3). The overall RMSE for CO was 0.28 and for $\mathrm{FGP}_{\mathrm{obs}}<1$, RMSE was 0.12 . Although this value indicates more error than the ND model, the producer's accuracy was better than the other sites at $83 \%$. Like WY, the CO model predicted only two below-average years as above average. Additionally, the mean bias for CO for all observations as well as $\mathrm{FGP}_{\mathrm{obs}}<1$ was 0.00 , indicating that it did not tend toward overestimation or underestimation.

Predictive performance earlier in the season was relatively consistent with the weights of the months for WY; most measures indicated poorer prediction with fewer months of precipitation as predictors. Values of TSS tended to decrease with fewer months, although the January-May value (0.52) was slightly higher than January-June (0.42), and the January-February and January-only values were actually higher than January-March. RMSE increased steadily for all observations as well as for $\mathrm{FGP}_{\text {obs }}<1$ as months were 
Table 2. Predictive accuracy of forage growth potential (FGP) using different periods of monthly precipitation data from January through June. Results were evaluated with "leave-one-out" cross validation. Measures of accuracy are the True Skill Statistic (TSS [Eq. 3]) for general classification, mean bias (MB [Eq. 4]), root mean square error (RMSE [Eq. 5]), producer's accuracy (the accuracy of predicting the observed class of FGP), and user's accuracy (the accuracy of the observation matching the predicted class of FGP). ${ }^{1}$

\begin{tabular}{|c|c|c|c|c|c|c|c|c|c|}
\hline \multirow[b]{2}{*}{ Location } & \multicolumn{4}{|c|}{ All observations } & \multicolumn{4}{|c|}{ Observed FGP $<1$} & \multirow{2}{*}{$\begin{array}{l}\text { Predicted FGP }<1 \\
\text { User's accuracy (\% }\end{array}$} \\
\hline & $\begin{array}{l}\text { Precipitation used } \\
\text { for prediction }\end{array}$ & MB & RMSE & TSS & $\begin{array}{l}\text { Mean value } \\
\text { of } F G P<1\end{array}$ & MB & RMSE & $\begin{array}{c}\text { Producer's } \\
\text { accuracy (\%) }\end{array}$ & \\
\hline \multicolumn{10}{|c|}{ Calibration } \\
\hline ND & January-June & 0.04 & 0.22 & 0.17 & 0.84 & -0.01 & 0.07 & 67 & 55 \\
\hline WY & January-June & -0.03 & 0.30 & 0.42 & 0.67 & -0.04 & 0.09 & 82 & 69 \\
\hline $\mathrm{CO}$ & January-June & 0.00 & 0.28 & 0.53 & 0.69 & 0.00 & 0.12 & 83 & 71 \\
\hline \multicolumn{10}{|c|}{ Cross validation } \\
\hline \multirow[t]{6}{*}{ ND } & January-June & 0.01 & 0.26 & 0.06 & - & -0.03 & 0.13 & 56 & 55 \\
\hline & January-May & -0.03 & 0.40 & 0.07 & - & -0.09 & 0.27 & 67 & 50 \\
\hline & January-April & 0.02 & 0.39 & 0.04 & - & -0.06 & 0.25 & 44 & 50 \\
\hline & January-March & -0.06 & 0.47 & 0.38 & - & -0.17 & 0.33 & 78 & 64 \\
\hline & January-February & -0.05 & 0.56 & 0.18 & - & -0.18 & 0.31 & 78 & 54 \\
\hline & January & -0.03 & 0.69 & -2.56 & - & -0.23 & 0.40 & 44 & 36 \\
\hline \multirow[t]{6}{*}{ WY } & January-June & -0.04 & 0.32 & 0.42 & - & 0.01 & 0.10 & 82 & 69 \\
\hline & January-May & -0.07 & 0.39 & 0.52 & - & -0.03 & 0.14 & 82 & 75 \\
\hline & January-April & -0.07 & 0.50 & 0.32 & - & -0.04 & 0.22 & 82 & 64 \\
\hline & January-March & -0.19 & 0.68 & -0.25 & - & -0.14 & 0.35 & 55 & 43 \\
\hline & January-February & -0.16 & 0.69 & -0.06 & - & -0.13 & 0.35 & 64 & 50 \\
\hline & January & -0.11 & 0.91 & 0.05 & - & -0.23 & 0.47 & 55 & 55 \\
\hline \multirow[t]{6}{*}{ CO } & January-June & -0.02 & 0.33 & 0.53 & - & -0.02 & 0.17 & 83 & 71 \\
\hline & January-May & -0.01 & 0.33 & 0.53 & - & -0.02 & 0.15 & 83 & 71 \\
\hline & January-April & -0.02 & 0.39 & 0.29 & - & -0.03 & 0.20 & 75 & 60 \\
\hline & January-March & -0.01 & 0.59 & 0.21 & - & -0.03 & 0.30 & 67 & 57 \\
\hline & January-February & -0.01 & 0.60 & 0.03 & - & -0.04 & 0.35 & 42 & 50 \\
\hline & January & -0.00 & 0.68 & 0.53 & - & 0.15 & 0.66 & 83 & 72 \\
\hline
\end{tabular}

${ }^{1}$ Values of predicted FGP $>1$ set to equal 1. ND indicates North Dakota; WY, Wyoming; and C0, Colorado.

removed from the cross validation. The producer's accuracy for $\mathrm{FGP}_{\mathrm{obs}}<1$ decreased from $82 \%$ to $55 \%$ without April, May, and June precipitation. CO showed some variation in predictive performance throughout the season. The TSS consistently declined as months were removed until only January was used, and it matched the January-June value of 0.53 . This may be an isolated effect of spurious correlation in the CO data, which is neither expected nor consistent with the other locations.
Producer's accuracy for $\mathrm{FGP}_{\text {obs }}<1$ also declined from $83 \%$ using January-June to $42 \%$ using January-February, then increased with only January back to $83 \%$. However, RMSE increased consistently as months were removed both for all observations and for $\mathrm{FGP}_{\text {obs }}<1$. Measures of predictive performance for ND with fewer months of precipitation did not consistently decline. The variability in the measures is likely the result of both skewed distribution of observations and correlations among monthly precipitation.

Table 3. The accuracy of prediction of forage growth potential (FGP) from the user's perspective including user's accuracy, the percent of the predicted class that correctly classified. See Table 2 for the producer's accuracies, the accuracy of prediction according to the observed class of FGP. ${ }^{1}$

\begin{tabular}{|c|c|c|c|c|c|c|c|c|c|c|}
\hline \multirow[b]{3}{*}{ Location } & \multirow[b]{3}{*}{ Months } & \multicolumn{6}{|c|}{ Predicted FGP $<1$} & \multicolumn{3}{|c|}{ Predicted FGP $\geq 1$} \\
\hline & & \multirow{2}{*}{$\begin{array}{c}\text { User's } \\
\text { accuracy } \\
(\%)\end{array}$} & \multicolumn{3}{|c|}{ Observed FGP $<1$} & \multicolumn{2}{|c|}{ Observed FGP $\geq 1$} & \multirow{2}{*}{$\begin{array}{c}\text { User's } \\
\text { accuracy } \\
(\%)\end{array}$} & \multirow{2}{*}{$\begin{array}{c}\text { Observed FGP }<1 \\
\text { Observed FGP } \\
(\text { mean } \pm \mathrm{SD})\end{array}$} & \multirow{2}{*}{$\begin{array}{c}\text { Observed FGP } \geq 1 \\
\text { Observed FGP } \\
(\text { mean } \pm \mathrm{SD})\end{array}$} \\
\hline & & & $\begin{array}{c}\text { Mean bias } \\
\text { (mean } \pm \mathrm{SD})\end{array}$ & $\begin{array}{c}\text { Predicted FGP } \\
(\text { mean } \pm \mathrm{SD})\end{array}$ & $\begin{array}{c}\text { Observed FGP } \\
\text { (mean } \pm \mathrm{SD})\end{array}$ & $\begin{array}{c}\text { Predicted FGP } \\
(\text { mea } \pm \mathrm{SD})\end{array}$ & $\begin{array}{c}\text { Observed FGP } \\
\text { (mean } \pm \mathrm{SD})\end{array}$ & & & \\
\hline \multirow[t]{3}{*}{ WY } & January-June & 69 & 0.00 & $0.63 \pm 0.22$ & $0.63 \pm 0.25$ & $0.95 \pm 0.03$ & $1.27 \pm 0.20$ & 75 & $0.83 \pm 0.18$ & $1.45 \pm 0.34$ \\
\hline & January-May & 75 & -0.01 & $0.61 \pm 0.26$ & $0.62 \pm 0.24$ & $0.83 \pm 0.15$ & $1.18 \pm 0.06$ & 78 & $0.88 \pm 0.11$ & $1.46 \pm 0.31$ \\
\hline & January-Apr & 62 & -0.06 & $0.56 \pm 0.33$ & $0.62 \pm 0.26$ & $0.79 \pm 0.10$ & $1.25 \pm 0.13$ & 63 & $0.81 \pm 0.13$ & $1.50 \pm 0.37$ \\
\hline \multirow[t]{3}{*}{$\mathrm{CO}$} & January-June & 71 & 0.02 & $0.69 \pm 0.16$ & $0.67 \pm 0.22$ & $0.86 \pm 0.06$ & $1.29 \pm 0.08$ & 82 & $0.78 \pm 0.15$ & $1.29 \pm 0.24$ \\
\hline & January-May & 71 & 0.02 & $0.69 \pm 0.15$ & $0.62 \pm 0.24$ & $0.82 \pm 0.09$ & $1.29 \pm 0.08$ & 82 & $0.78 \pm 0.15$ & $1.29 \pm 0.24$ \\
\hline & January-April & 63 & 0.06 & $0.73 \pm 0.18$ & $0.67 \pm 0.22$ & $0.78 \pm 0.16$ & $1.30 \pm 0.07$ & 78 & $0.78 \pm 0.15$ & $1.28 \pm 0.28$ \\
\hline
\end{tabular}

${ }^{1} \mathrm{SD}$ indicates standard deviation; WY, Wyoming; and $\mathrm{CO}$, Colorado. 


\section{DISCUSSION}

Results from all three locations show that the DC generally predicted reductions in FGP resulting from drought based on monthly precipitation. Similar to published models (Derner and Hart 2007), forage production in WY was most sensitive to drought in April, May, and June. In CO, FGP was most sensitive to drought in April and May, with secondary correlation to precipitation in January and March.

Because our interest was a decision model, our research differs from previous research in that we evaluated predictive accuracy with cross validation. The WY and CO models generate useful information, as indicated by TSS values greater than zero, a measure of how well the model predicts if FGP will be below or above average, and the model error statistics (MB and RMSE). For ND the relationship between FGP and precipitation is not as strong. The model discriminated between below- and above-average FGP only slightly better than guessing (TSS $=0.17$ ). Our $19 \mathrm{yr}$ of data included only $2 \mathrm{yr}$ with less than $88 \%$ of average FGP, potentially indicating that the DC is less useful for the ND site. For these two drought years, the model predicted FGP of 0.72 and 0.51 and underestimated with similar error as that of the WY model. Also similar to the WY model, FGP in ND is sensitive to drought in May and June.

Earlier prediction of reduced FGP due to drought can help users make important stocking decisions in order to improve profitability and rangeland sustainability (Andales et al. 2006). With our simple model, the weights for precipitation in April, May, and June are large compared to other months. Consequently, earlier prediction will require reasonably accurate forecasts of precipitation in April, May, and June. Some western states are dominated by the warm season rather than the cool season (Torell et al. 2010, 2011). In these locations, PSC may not occur until September (Pieper et al. 1974). Precipitation for the previous fall as well as the summer months can be added to improve predictive accuracy. However, when summer precipitation drives forage production, it will be difficult to use this tool to make stocking decisions earlier in the season.

Because the DC uses linear regression, two different distributions of monthly precipitation may (incorrectly) predict the same FGP. That is, the model is nonunique. For example, if the weights were 0.24 for April and 0.26 for May, the same FGP would be predicted with no precipitation in April and precipitation of 0.92 in May as with precipitation of 1.0 in April and none in May. The linear model does not allow severe drought in a previous month to limit a plant's ability to use above-average precipitation in a following month. Such model responses would require a penalty function for precipitation below established thresholds. However, such complex models would need to be calibrated using more data, which typically are not available. Prediction also may be improved using effective precipitation during a month to account for precipitation that is not used for forage growth such as surface runoff associated with large precipitation events.

Predictive accuracy as shown in Tables 2 and 3 is just one component of the value of a model as a decision support tool. Decision makers consider that some errors in prediction are more costly than others. For example, the cost of buying unnecessary feed as a result of an erroneous prediction of low
FGP may be less costly than low animal weight and damage to rangeland as a result of the model mistakenly not predicting low FPG. There are three types of errors in decision making based on prediction with this tool: mitigating for drought when there will not be a drought $\left(\mathrm{FGP}_{\text {pred }}<1, \mathrm{FGP}_{\text {obs }}>1\right)$, not mitigating for drought when there will be a drought $\left(\mathrm{FGP}_{\text {pred }} \geq 1, \mathrm{FGP}_{\text {obs }}<1\right)$, or too little or too much mitigation $\left(\mathrm{FGP}_{\text {pred }}<1, \mathrm{FGP}_{\mathrm{obs}}<1\right)$. The likelihoods and severity of these errors are shown for WY and $\mathrm{CO}$ in Table 3. Actual values of above-average yields $\left(\mathrm{FGP}_{\mathrm{obs}}>1\right)$ were used in constructing the table rather than assuming a maximum value of one. This was done to show that FGP is expected to be correctly predicted to be above average in the years with the highest production (FGP $>1$ ).

Table 3 emphasizes the decision maker's perspective. For example, with precipitation for January through June as predictors, the WY model correctly predicted FGP $<1$ in $82 \%$ of the years with reduced FGP (producer's accuracy), and the CO model correctly predicted FGP $<1$ for $83 \%$ of the years on record. However, a decision maker may be more interested in the user's accuracy-how often actual FGP $\geq 1$ when $\mathrm{FGP}<1$ is predicted (Table 3). In the WY model, a prediction of FGP $<1$ is often correct (user's accuracy $=69 \%$ ). In correctly predicted drought years, the WY model neither overestimates nor underestimates FGP $(\mathrm{MB}=0.00)$. In nondrought years that the WY model incorrectly predicts as drought, $\mathrm{FGP}_{\text {pred }}=$ $0.95 \pm 0.03$. In CO, the user's accuracy when predicted FGP $<1$ is $71 \%$, and mean bias is 0.02 , indicating that the CO model overestimates production by $2 \%$. The user's accuracy for a prediction of $\mathrm{FGP} \geq 1$ is $75 \%$ for WY, but these results indicate that FGP averages 0.83 in the few years when FGP $\geq 1$ is mistakenly predicted. The user's accuracy for $\mathrm{CO}$ when predicted FGP $>1$ is $82 \%$. In the 2 yr when FGP $>1$ was mistakenly predicted (misclassified), the average actual FGP was 0.78 .

\section{IMPLICATIONS}

Reduced FGP as a result of drought can be predicted beginning in May at some locations, generally dominated by cool-season grasses, with a weighted average of monthly total precipitation. Accuracy of predictions earlier in the season than May will depend on the accuracy of forecasting precipitation. Model utility may also be limited by the dominance of warm-season grasses, as these sites respond to summer and fall precipitation, making earlier predictions more difficult.

The model is simple and quick to use, which are essential characteristics of any decision tool. It is incorporated in a simple software program with the guidance of rangeland managers. Predictions are easily interpreted as FGP relative to average production at a location, and the monthly precipitation is readily available and can be automatically acquired by the spreadsheet from weather station data available on the Internet. The TSS (Eq. 3) results indicate that the tool is useful for discriminating drought effects on FGP classification being above or below the long-term average, which is a basis for stocking decisions. Furthermore, the producer's accuracy for drought years based on cross validation shows that the decision tool is more accurate than simply assuming the long-term mean of those below-average years, which implies that it provides a 
quantitative advantage to producers for their stocking decisions in drought years. Use of this decision tool is most likely limited by the available data used to determine the weights of monthly precipitation for prediction of FGP. The quantitative measures of model accuracy computed here provide potential users with useful information for applying the DC at other locations.

\section{LITERATURE CITED}

Allouche, 0., A. Tsoar, and R. Kadmon. 2006. Assessing the accuracy of species distribution models: Prevalence, kappa and the true skill statistic (TSS). Journal of Applied Ecology 43:1223-1232.

Andales, A. A., J. D. Derner, L. R. Ahuja, and R. H. Hart. 2006. Strategic and tactical prediction of forage production in northern mixed-grass prairie. Rangeland Ecology \& Management 59:576-584.

BIondinI, M. E., AND L. Manske. 1996. Grazing frequency and ecosystem processes in a northern mixed prairie, USA. Ecological Applications 6:239-256.

BiondinI, M. E., B. D. Patton, and P. E. Nyren. 1998. Grazing intensity and ecosystem processes in a northern mixed-grass prairie, USA. Ecological Applications 8:469-479.

BRIGGS, J. M., AND A. K. KNAPP. 1995. Interannual variability in primary production in tallgrass prairie: climate, soil moisture, topographic position, and fire as determinants of aboveground biomass. American Journal of Botany 82:10241030.

Colorado State University, Shortgrass Steppe Long Term Ecological Research. 2013. SGS-LTER standard production data. Available at: http://www.sgsiter.colostate. edu/dataset_view.aspx?id=anpp. Accessed 15 February 2013.

Congalton, R. G. 1991. A review of assessing the accuracy of classifications of remotely sensed data. Remote Sensing of Environment. 37:35-46.

CurRie, P. O., And G. Peterson. 1966. Using growing-season precipitation to predict crested wheatgrass yields. Journal of Range Management 19:284-288.

DAHL, B. E. 1963. Soil moisture as predictive index of forage yield for the sandhills range type. Journal of Range Management 16:128-132.

Derner, J. D., and R. H. Hart. 2007. Grazing-induced modifications to PSC in northern mixed-grass prairie. Rangeland Ecology \& Management 60:270-275.

ECkBLAD, M. 2012. Drought dries up cattle market. Wall Street Journal. Available at http://online.wsj.com/article/SB10000872396390443545504 $577563241883627730 . \mathrm{html}$. Accessed 27 June 2013.

Frank, A. B., S. Bittman, and D. A. Johnson. 1996. Water relations of cool-season grasses. Agronomy Monograph 34:127-164.

Gillen, R. L., AND P. L. Sims. 2006. Stocking rate and weather impacts on sand sagebrush and grasses: a 20-year record. Rangeland Ecology \& Management 59:145-152.

Hawkins, D. M., S. C. BASAK, AND D. Mllls. 2003. Assessing model fit by crossvalidation. Journal of Chemical Information and Modeling. 43:579-586.

Heitschmidt, R. K., K. D. Klement, and M. R. Haferkamp. 2005. Interactive effects of drought and grazing on Northern Great Plains rangelands. Rangeland Ecology \& Management 58:11-19.

Lauenroth, W. K., and 0. E. Sala. 1992. Long-term forage production of North American shortgrass steppe. Ecological Applications 2:397-403.

Milchunas, D. G., J. R. Forwood, and W. K. LauenRoth. 1994. Productivity of long-term grazing treatments in response to seasonal precipitation. Journal of Range Management 47:133-139.

North Dakota Agricultural Weather Network. 2008. nDAWN Center. Available at: http://ndawn.ndsu.nodak.edu. Accessed 27 June 2013.

Parker, C. G., and S. Campion. 1997. Improving the uptake of decision support systems in agriculture. In: H. Kure, I. Thysen, and A. R. Kristensen [EDS.]. First European Conference for Information Technology in Agriculture; Copenhagen, Denmark; 15-18 June 1997. p. 129-134.
Pieper, R. D., C. H. Herbel, D. D. Dwyer, and R. E. Banner. 1974. Management implications of herbage weight changes on native rangeland. Journal of Soil and Water Conservation 29:227-229.

SCHWINNING, S., B. I. StaRR, AND J. R. EHLERINGer. 2005. Summer and winter drought in a cold desert ecosystem (Colorado Plateau) part II: effects on plant carbon assimilation and growth. Journal of Arid Environments 61:61-78.

Smart, A. J., B. H. Dunn, P. S. Johnson, L. Xu, and R. N. Gates. 2007. Using weather data to explain herbage yield on three Great Plains plant communities. Rangeland Ecology \& Management 60:146-153.

SmoLIAK, S. 1956. Influence of climatic conditions on forage production of shortgrass rangeland. Journal of Range Management 9:89-91.

SмоLIAK, S. 1986. Influence of climatic conditions on production of Stipa-Bouteloua prairie over a 5-year period. Journal of Range Management 39:100-103.

Thurow, T. L., AND C. A. Taylor, JR. 1999. Viewpoint: the role of drought in range management. Journal of Range Management 52:413-419.

Torell, L. A., K. C. McDaniel, And V. Koren. 2011. Estimating grass yield on blue grama range from seasonal rainfall and soil moisture measurements. Rangeland Ecology \& Management 64:56-66.

Torell, L. A., S. Murugan, and 0. A. Ramirez. 2010. Economics of flexible versus conservative stocking strategies to manage climate variability risk. Rangeland Ecology \& Management 63:415-425.

Western Regional Climate Center. 2008. Western Regional Climate Center. Available at: http://www.wrcc.dri.edu. Accessed 27 June 2013.

Wiles, L. J., G. H. Dunn, J. Printz, B. Patton, and A. Nyren. 2011 Spring precipitation as a predictor for peak standing crop of mixed-grass prairie Rangeland Ecology \& Management 64:215-222.

Wilkerson, G., L. Wiles, and A. Bennett. 2002. Weed management decision models: pitfalls, perceptions, and possibilities of the economic threshold approach. Weed Science 50:411-424.

\section{APPENDIX 1}

\section{Drought Calculator Availability}

The Drought Calculator (DC) is available as a spreadsheet or a stand-alone program that can be downloaded to the user's computer from the USDA-ARS software page (http:// arsagsoftware.ars.usda.gov). Calibrated DCs for 11 western states are available online. Users are required to set up a free account and provide their name and email address. Monthly weights are calculated using our optimization model using data from each state, and in some cases of warm-season grasses, summer months and previous fall months are included in the analysis. Long-term average precipitation data are available online by state but comes preloaded in the DC for many locations. Monthly precipitation data by year and month from weather stations can be acquired from several sources (e.g., newspapers, television, and personally collected). Users have the option to input their own long-term average and current precipitation in addition to using the data available on the program. The DC also includes links to various Web sites, enabling users to locate appropriate precipitation data efficiently. For example, the National Oceanic and Atmospheric Administration's National Climatic Data Center links to a database searchable by location and product. After the precipitation data are entered, the DC calculates the most likely percentage of average forage production for the coming year. This can be useful information for ranchers who would like to make stocking decisions earlier in the season. 